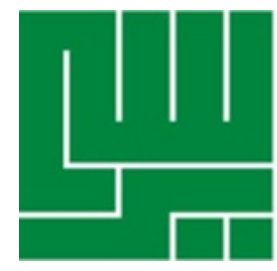

\title{
Peran Trait Kepribadian terhadap Perilaku Mengemudi Pengendara Bermotor di Jakarta
}

\section{The Role of Personality Trait to the Driving Behavior in Motorcycle Rider in Jakarta}

\author{
Arif Triman, Sunu Bagaskara \\ Fakultas Psikologi Universitas YARSI \\ Menara YARSI, Letjend Suprapto Kav.13, Cempaka Putih, Jakarta, 10510, Indonesia \\ arif.triman@yarsi.ac.id; sunu.bagaskara@yarsi.ac.id
}

KATA KUNCI Kepribadian, Big Five Personality, Risky Drivng Behaviour

KEYWORDS Personality, Big Five Inventory, Risky Driving Behaviour

ABSTRAK Meningkatnya angka kecelakaan tiap tahunnya menjadi permasalahan sendiri di Indonesia. Beberapa penelitian terdahulu menunjukkan faktor internal dari pengemudi seperti kepribadian berhubungan dengan perilaku para pengemudi di jalan raya. Penelitian ini dilakukan untuk melihat pengaruh kepribadian terhadap perilaku mengemudi berisiko (RDB) pada pengendara mobil dan sepeda motor di wilayah JABODETABEK. Sebanyak 318 pengemudi dalam rentang umur 16 sampai 57 tahun telah menyelesaikan kuesioner Big Five Inventory dan perilaku mengemudi berisiko (RDB) yang disebarkan secara online. Analisis regresi digunakan untuk melihat pengaruh antara kedua variabel ini. Hasil analisa menemukan adanya pengaruh yang signifikan trait neuroticism, agreeableness dan conscientiousness terhadap RDB. Hasil penelitian ini turut mendukung penelitian terdahulu di mana kepribadian memegang peranan penting dalam perilaku mengemudi yang aman

ABSTRACT The increased number of accidents is a big problem in Jakarta. Past researchs found that, internal factor like personality has a significant relationship with driving behaviour. This study is intented to examine the role of personality trait in risky driving behaviour among car and motorcycle drivers in JABODETABEK. There are 318 participants who completed an online questionnaire assessing five traits of personality with $B F I$ and RDB Scale to measure risky driving behavior. Using regression analysis, it was found that 3 of 5 personality trait (neuroticism, agreeableness and conscientiousness) were found to have significant role in risky driving behavior. In conclusions, result of this study is consistent with previous studies which found personality as an important factor in road safety behavior.

\section{PENDAHULUAN}

Meningkatnya angka kematian telah menjadi problematika dalam dunia kesehatan pada masa sekarang ini (Sucha \& Chernocova, 2016). Studi yang dilakukan WHO (2004) menemukan salah satu faktor yang menyebabkan tingginya angka kematian adalah keceakaan lalu lintas. Data dari WHO ini juga mencatat telah terjadi 1,5 juta kematian yang disebabkan oleh kecelakaan di jalan raya. Ditambah lagi, 50 juta orang menjadi korban luka yang disebabkan oleh kecelakaan di jalan raya. Kondisi yang sama juga ditemukan di Indonesia. Data KORLANTAS POLRI (2015) mendapati 
telah terjadi 5000 angka kematian dari 20000 ribu angka kecelakaan yang terjadi di Indonesia. Angka ini harus menjadi perhatian bagi kita karena hampir 25\% dari jumlah kecelakaan yang terjadi akan menyebabkan korban jiwa. Data ini diperkuat dengan temuan dari World Report on Road Traffic Injury Prevention (2004), dimana negara maju memiliki angka kecelakaan yang cenderung menurun dan sebaliknya negara berkembang seperti Indonesia memiliki kecenderungan peningkatan angka kecelakaan setiap tahunnya. Di sisi lain, data global safety report on road safety (2015) yang dikeluarkan oleh WHO, mendapati jumlah kecelakaan di tiap tahun terus meningkat sebesar $4 \%$ setiap tahunnya. Lebih buruk lagi, laporan WHO ini juga menemukan bahwa kecelakaan di jalan raya telah menjadi penyebab kematian paling tinggi pada populasi dunia usia produktif yaitu usia 15-29 tahun. Maka dari itu, penting sekiranya untuk memahami penyebab terjadinya suatu kecelakaan.

Apabila dilihat dari faktor yang menyebabkan terjadinya kecelakaan di jalan raya, $90 \%$ dari faktor tersebut adalah faktor manusia dan $10 \%$ disebabkan oleh faktor lainnya (Bachoo, Bhagwanjee \& Govender, 2013; Mikler \& Almakadma, 2016; Sucha \& Chernocova, 2016). Faktor manusia ini telah menjadi perhatian tersendiri bagi para peneliti dalam mengkaji penyebab kecelakaan di jalan raya. Penelitian sebelumnya menemukan banyak faktor internal yang bisa menyebabkan terjadinya kecelakaan pada seorang pengemudi, diantaranya faktor kepribadian, kognitif, dan lainnya. Akan tetapi, faktor kepribadian dianggap penting untuk diteliti karena kepribadian tentunya akan merefleksikan gaya mengemudi seorang individu.

Berdasarkan beberapa penelitian sebelumnya, faktor kepribadian menjadi faktor internal yang berhubungan dengan perilaku yang membahayakan di jalan raya agresif saat mengemudi, mengemudi yang beresiko, dan lainnya (Machin \& Sankey, 2007; Zhang, et al, 2017). Selain itu beberapa trait kepribadian ditemukan memiliki hubungan dengan perilaku berbahaya saat dijalan raya, seperti trait neuroticism dan agreeableness dengan perilaku melanggar aturan lalu lintas (Dahlen, Martin, Ragan, \& Kuhlman, 2005) dan trait conscientiousness dengan mengemudi diatas kecepatan aman serta mengemudi mencari sensasi (Schwebel, Severson, Ball \& Rizzo, 2006).Akan tetapi belum ada penelitian terdahulu yang meneliti seberapa kuat pengaruh trait kepribadian tersebut. Di sisi lain, Machin \& Sankey (2007) menyatakan mengemudi diatas kecepatan batas aman, melanggar aturan lalu lintas merupakan bagian dari risky driving behavior (RDB). Penelitian terdahulu telah mengkaji bagaimana keterkaitan RDB dengan aspek-aspek lain yang dimiliki oleh manusia. Seperti, hubungan antara faktor kognitif dengan RDB (Sucha \& Chernocova, 2016), RDB dengan gaya hidup (Bina, Graziano \& Bonino, 2006) RDB dengan persepsi terhadap resiko (Machin \& Sankey, 2007) serta keterkaitan RDB dengan Sifat impulsif, emosi marah dan perilaku mencari sensasi (Bachoo, Bhagwanjee \& Govender, 2013).

RDB dapat dilihat dari sikap yang tidak peduli terhadap sekitar, kecepatan mengemudi yang melampaui batas dan ketidakpatuhan terhadap peraturan lalu lintas (Musselwhite, 2006; Machin \& Sankey, 2007). Sementara itu, bila ditelaah berdasarkan teori kepribadian Big Five, perilaku mengemudi berisiko ini bisa dideskripsikan melalui kelima trait yang dimiliki teori Big Five ini. Penelitian sebelumnya juga menemukan variabel kepribadian manusia bisa menjadi indikator yang mempengaruhi perilaku mengemudi berisiko (RDB) di jalan raya (Dahlen \& White, 2006; Bachoo, Bhagwanjee \& Govender, 2013; Sucha \& Cernochova, 2016). Maka dari itu, dengan adanya faktor kepribadian sudah semestinya berhubungan dengan Perilaku 
RDB pada pengemudi kendaraan bermotor di jalan raya. Berikut penjelasan tentang contoh perilaku yang bisa muncul dari seorang individu berdasarkan teori Big Five.

Beberapa penelitian diatas telah menelusuri hubungan RDB dengan bagian-bagian dari kepribadian manusia. Seperti adanya sifat marah, impulsif, perilaku mencai sensasi yang merupakan sebagian karakter yang dimiliki oleh kepribadian manusia. Kepribadian tidak serta merta mampu memprediksi kecelakaan di jalan raya, akan tetapi secara tidak langsung mempengaruhi perilaku mengemudi yang berisiko memunculkan terjadinya kecelakaan (Constantinou, Panayiotou, Konstantinou, Ladd \& Kapardis, 2011). Oleh karena itu, peneliti tertarik untuk melakukan penelitian yang lebih mendalam untuk melihat pengaruh trait kepribadian terhadap RDB pada para pengemudi di Indonesia.

\section{METODE PENELITIAN}

\section{Desain Penelitian}

Penelitian ini dengan metode penelitian kuantitatif dengan rancangan penelitian kausalitas. Variabel bebas dalam penelitian ini adalah trait kepribadian yang menggunakan alat ukur Big Five Inventory (BFI). Selain itu, variabel terikat dalam penelitian ini adalah Risky Driving Behaviour (RDB) dengan menggunakan alat ukur Risky Driving Behaviour Scale. Populasi dan Sampel Penelitian

Populasi penelitian ini adalah keseluruhan pengendara kendaraan bermotor di daerah JABODETABEK. Karena jumlah sampel yang besar, maka peneliti menggunakan teknik insidental sampling. Teknik ini digunakan karena jumlah pengendara kendaraan bermotor yang besar dan tidak diketahui jumlah pastinya. Peneliti menggunakan siapa saja yang ditemui dan bisa mengendarai kendaraan bermotor sebagai sampel penelitian. Untuk mengontrol populasi dan mempertimbangkan faktor-faktor yang bisa berpengaruh dalam penelitian ini, maka peneliti menyertakan beberapa faktor demografi dalam alat ukur yang dipakai. Beberapa faktor demografi di antaranya: jenis kelamin dan jenis kendaraan bermotor yang dimiliki.

\section{Instrumen Penelitian}

Penelitian ini menggunakan 2 alat ukur yakni Big Five Inventory (BFI) Scale untuk mengukur kepribadian dan Risky Driving Behaviour (RDB) Scale untuk mengukur perilaku mengemudi berisiko. BFI sendiri memiliki 5 dimensi atau trait untuk menjelaskan kepribadian manusia, diantaranya : Trait Neurotism (4 item), Trait Extraversion (5 item), Openess (6 item), Agreeableness (6 item), Conscientiousness (6 item). Total item dari alat ukur ini adalah 27 item. Alat ukur ini sebelumnya telah diadaptasi kedalam Bahasa Indonesia serta dilakukan uji validitas dan reliabilitasnya. Sementara itu, pengukuran RDB menggunakan alat ukur Risky Driving Behaviour Scale dari Musselwhite (2006). Alat ukur ini berbentuk unidimensional serta telah diadaptasi kedalam bahasa Indonesia. Alat ukur ini terdiri dari 16 item yang mengukur perilaku mengemudi beresiko. Dalam penelitian ini, peneliti melakukan uji reliabilitas lagi terkait dengan perbedaan karakteristik sampel yang digunakan. Hasil uji reliabilitas alat ukur BFI ini menggunakan Alpha Cronbach bisa dilihat pada tabel 1. Dari hasil analisa, nilai Alpha Cronbach dari masing-masing trait kepribadian berada para rentang 0,67 $-0,83$. Sementara itu, alat ukur RDB juga diuji kembali reliabilitasnya sengan nilai Alpha Croncbach 0,89. Azwar (2002) menyatakan nilai minimal Alpha Cronbach yang dapat diterima adalah 0,6. Untuk lebih detilnya, hasil pengujian reliabilitas diuraikan pada Tabel 1. 
Tabel 1. Nilai Alpha Cronbach Alat Ukur BFI dan RDB

\begin{tabular}{cccc}
\hline Variabel & Mean & SD & $\begin{array}{c}\text { Koefisien } \\
\text { Alpha }\end{array}$ \\
\hline Neurotism & 12.23 & 3.49 & 0.81 \\
Extraversion & 18.28 & 3.14 & 0.74 \\
Openness & 22,07 & 3.60 & 0.77 \\
Agreeableness & 27.91 & 3.40 & 0.67 \\
Conscientiousness & 21.96 & 3.84 & 0.83 \\
RDB & 34.45 & 10.40 & 0.89 \\
\hline
\end{tabular}

\section{Analisis Data}

Untuk melakukan analisa data, peneliti menggunakan program Statistical Package for Social Scientists (SPSS) versi 22. Analisa deskriptif digunakan untuk mendeskripsikan data seperti mean, persentase dan standar deviasi. Sementara itu, untuk melihat pengaruh trait kepribadian terhadap RDB, peneliti menggunakan uji multiple regression dengan metode Enter.

\section{HASIL}

\section{Analisis Deskriptif}

Pengambilan data dilakukan kepada 318 orang yang berada pada rentang usia remaja dan dewasa $(M=$ $25.84, S D=7.92)$. Sebanyak $42 \%(133$ orang) sampel berada pada rentang usia remaja dan 58\% (185 orang) sampel berada pada rentang usia dewasa. Berdasarkan pembagian jenis kelamin, 47\% sampel merupakan pengendara lakilaki (149 orang) dan 53\% (168 orang) sampel merupakan pengendara perempuan. Jika dilihat dari jenis kendaraan yang digunakan, 27\% (86 orang) responden adalah pengguna mobil, $43 \%$ (136 orang) responden pengguna sepeda motor dan $30 \%$ (96 orang) responden menggunakan kedua jenis kendaraan bermotor ini. Deskripsi data ini lebih detil terlihat di Tabel 2.

Tabel 2. Deskripsi Data

\begin{tabular}{lcc}
\hline \multicolumn{1}{c}{ Variabel } & Jumlah & Persentase \\
\hline Jenis Kelamin & 149 & $47 \%$ \\
Laki-Laki & 168 & $53 \%$ \\
$\quad$ Perempuan & & \\
Jenis Kendaraan & 86 & $27 \%$ \\
Mobil & 136 & $43 \%$ \\
Sepeda Motor & 96 & $30 \%$ \\
$\quad$ Keduanya & & \\
Usia & 133 & $42 \%$ \\
Remaja & 185 & $58 \%$ \\
$\quad$ Dewasa & & \\
\hline
\end{tabular}

\section{Analisis Regresi}

Sebelum melakukan analisis regresi, peneliti melakukan uji korelasi untuk menentukan trait kepribadian mana yang memiliki hubungan dengan RDB. Oleh karena itu, hasil uji korelasi dapat dilihat dari tabel 3. 
Tabel 3. Uji korelasi trait kepribadian dengan RDB

\begin{tabular}{cc}
\hline Trait Kepribadian & $\mathrm{r}$ \\
\hline Openness & -0.093 \\
Conscientiousness & $-0.344^{* *}$ \\
Extraversion & $-0,212^{* *}$ \\
Agreeableness & $-0.315^{* *}$ \\
Neurotism & $0.234^{* *}$ \\
\hline
\end{tabular}

pengendara kendaraan motor maka RDB akan mencapai sebesar 57.174.

Berdasarkan uji korelasi, didapatkan bahwa trait opennes tidak memiliki hubungan yang signifikan dengan perilaku RDB. Sedangkan keempat trait Conscientiousness, Extraversion, Agreeableness, dan Neurotism memiliki hubungan yang signifikan dengan RDB. Maka dari itu, uji regresi yang dilakukan hanya menggunakan keempat trait kepribadian yang memiliki hubungan yang signifikan saja.

Langkah berikutya, peneliti melakukan uji normalitas dan linearitas sebagai syarat lain untuk terpenuhinya suatu uji regresi. Hasil perhitungan dengan menggunakan metode KolmogorovSmirnov menunjukkan bahwa data penelitian ini berdistribusi normal (KS Z = $0.64, \mathrm{p}=.814)$. Sementara itu, hasil uji linearitas menunjukkan bahwa trait kepribadian memiliki hubungan yang linear dengan perilaku mengemudi beresiko pada pengendara $(\mathrm{F}(\mathrm{df})=13.33$, $\mathrm{p}=.000)$. Dengan demikian, hasil uji normalitas dan linearitas kedua variabel memenuhi prasyarat untuk dilakukan uji regresi. Hasil uji regresi untuk menjawab pertanyaan penelitian dapat dilihat pada Tabel 4.

Berdasarkan hasil uji regresi, diketahui bahwa trait kepribadian berperan sebesar $15.9 \%$ terhadap RDB dan sebesar $84.1 \%$ dipengaruhi oleh faktor lain. Besarnya pengaruh ini terlihat dari nilai $\mathrm{R}$ $=0.399$ dan nilai $R^{2}=0.159$. Kemudian berdasarkan uji regresi didapatkan konstanta (a) sebesar 57.174 yang menunjukkan bahwa jika tidak ada pengaruh faktor kepribadian pada
Tabel 4. Uji Regresi Trait Kepribadian terhadap RDB

\begin{tabular}{cccc}
\hline & $\mathrm{B}$ & Beta & $\mathrm{t}$ \\
\hline (Constant) & 57.174 & & - \\
Conscientiousnes & - & - & - \\
$\mathrm{s}$ & $0.589 *$ & 0.22 & 3.33 \\
& $*$ & 6 & 2 \\
Extraversion & 0.163 & 0.05 & 0.76 \\
& & 1 & 8 \\
Agreeableness & - & - & - \\
& $0.606^{*}$ & 0.20 & 3.23 \\
Neuroticism & $0.339 *$ & 0.11 & 2.10 \\
& \multicolumn{3}{c}{8} \\
\hline Ket: **: signifikan pada level 0.01, \\
*: signifikan pada level 0.05
\end{tabular}

Berdasarkan hasil uji regresi, didapatkan persamaan regresi $\mathrm{RDB}=$ $57.174+(-0,598)$ Conscientiousness $+(-$ 0.606) Agreeableness $+\quad(0.339)$ Neuroticsm. Berdasarkan persamaan ini, nilai (-0.598) Conscientiousness merupakan koefisien regresi yang menunjukkan setiap penambahan 1 poin untuk trait conscientiousness maka akan terdapat penurunan RDB sebesar 0.598. Sedangkan nilai (-0.606) Agreeableness merupakan koefisien regresi yang menunjukkan setiap penambahan 1 poin untuk trait agreeableness maka akan terdapat penurunan RDB sebesar 0.606. Disamping itu, nilai( 0.339) Neuroticism merupakan koefisien regresi yang menunjukkan setiap penambahan 1 poin untuk trait neurotism maka akan terdapat peningkatan RDB sebesar 0.303. Di sisi 
lain, trait Extraversion tidak dimasukkan ke dalam persamaan karena tidak ditemukan pengaruh yang signifikan trait ini terhadap perilaku RDB.

Peneliti melakukan analisis tambahan untuk melihat perbedaan RDB berdasarkan data demografis yang secara teoretis diperkirakan mempengaruhi RDB. Hasil uji beda menunjukkan bahwa terdapat perbedaan yang signifikan pada perilaku RDB berdasarkan jenis kelamin para pengendara bermotor, $\mathrm{t}=4,574$ $p<0.01$. Dimana pengendara laki-laki $(M=$ $37.11, S D=11.01$ ) cenderung lebih beresiko saat mengemudi dibandingkan pengendara perempuan $(M=32.11, \mathrm{SD}=$ 8.44).

Tabel 5. Uji Beda RDB berdasarkan Jenis Kelamin

\begin{tabular}{ccccc}
\hline $\begin{array}{c}\text { Jenis } \\
\text { Kelamin }\end{array}$ & Mean & $S D$ & $\mathrm{t}$ & Sig. \\
\hline Laki-Laki & 37.11 & 11.01 & 4.574 & 0.000 \\
Perempuan & 32.10 & 8.44 & & \\
\hline
\end{tabular}

\section{DISKUSI}

Sebelum menganalisa pengaruh trait kepribadian terhadap perilaku RDB, peneliti telah menguji hubungan kedua variabel ini. Dari hasil uji korelasi, empat dari lima trait kepribadian memiliki hubungan yang signifikan dengan RDB. Hanya trait Openness yang tidak berkorelasi. Hasil temuan ini sejalan dengan temuan dari penelitian sebelumnya yang menyatakan trait neurotism, extraversion, conscientiousness dan agreeableness memiliki hubungan dengan perilaku RDB (Fernandez, Guerrero, Chaparro, Merino \& Jenchura, 2016; Tao, Zhang, \& Qu, 2017). Oleh karena itu, analisis regresi dilakukan hanya melibatkan keempat trait kepribadian ini terhadap perilaku RDB. Berdasarkan hasil uji regresi, didapatkan adanya pengaruh positif trait neuroticism terhadap RDB. Sedangkan trait conscientiousness dan agreeableness memiliki pengaruh negatif terhadap RDB. Manakala trait extraversion tidak memiliki pengaruh secara signifikan terhadap RDB itu sendiri.

Trait neuroticism memiliki pengaruh positif dalam meningkatkan perilaku RDB pada pengendara kendaraan bermotor. Apabila dilihat dari ciri-ciri orang yang memiliki trait Neurotism yang tinggi, seperti cemas, gugup dan kurang mampu mengelola emosi akan mempengaruhi munculnya perilakuperilaku mengemudi yang berisiko (Jhon \& Pervin, 1999; Sabates, Roca \& Garcia, 2012). Menurut Dahlen, Martin, Ragan, dan Kuhlman (2005) trait neuroticism sangat berkaitan dengan perilaku mengemudi beresiko, agresif, mencari sensasi, impulsif bahkan perilaku yang mengarah pada gangguan secara klinis. Constantinou, Panayiotou, Ladd dan Kapardis, (2011) juga menyatakan individu yang impulsif mengindikasikan trait Neurotism yang tinggi pada faktor kepribadian. Penelitian yang dilakukan oleh Wickens, Toplak dan Wiesenthal (2008) menemukan pengemudi yang memiliki kecenderungan impulsif lebih sering terlibat dalam pelanggaran peraturan lalu lintas dibandingkan pengemudi pada umumnya. Hal ini dikarenakan pengemudi impulsif sangat dipengaruhi oleh mood, mudah tersinggung dan sangat mudah meluapkan perasaannya (Whiteside \& Lynam, 2001). Dengan ciri seperti ini sangatlah sesuai dengan individu dengan RDB yang tinggi. Tidak hanya mempengaruhi RDB, penelitian sebelumnya membuktikan trait ini sangat erat kaitannya dengan perilaku negatif lain di jalan raya, seperti anger driving, aggression driving, anxious driving, dll (Bachoo, Bhagwanjee \& Govender, 2013; Schwebel, Severson, Ball \& Rizzo, 2006; Sârbescu, Costea, Rusu, 2012).

Hasil temuan lain dari penelitian ini adalah trait conscientiousness yang berpengaruh negatif terhadap perilaku RDB. Trait conscientiousness sangat berhubungan dengan keteraturan dan kepatuhan pengemudi saat berkendara (Chen, 2009). Trait conscientiousness 
sendiri merefleksikan kedisiplinan, tanggung jawab, dan keteraturan. Pengemudi yang dengan kecenderungan conscientiousness yang tinggi akan memperlihatkan perilaku mengemudi yang aman (Schwebel, Severson, Ball \& Rizzo, 2006). Selain itu, hasil penelitian ini juga sejalan dengan beberapa penelitian terdahulu yang menyimpulkan trait ini dapat memprediksi penurunan tingkat kecelakaan, perilaku ugal-ugalan serta kedisiplinan di jalan raya (Arthur \& Graziano, 1996; Arthur \& Doverspike, 2001; Zhang, et al, 2017).

Trait Agreeableness juga memiliki pengaruh negatif terhadap RDB. Hal ini menunjukkan pengendara yang memiliki kecenderungan pada trait agreeableness akan mengurangi kemungkinan munculnya perilaku mengemudi beresiko. Hasil temua ini didukung oleh penelitian yang dilakukan oleh (Lucidi, Mallia, Lazuras \& Violani, 2014). Penelitian ini menghasilkan temuan bahwa subtrait dari Agreeableness yaitu altruism erat kaitannya dengan perilaku taat di jalan raya. sebaliknya sub trait ini berkorelasi negatif dengan pelanggaran aturan lalu lintas. Individu dengan kecenderungan yang tinggi pada trait agreeableness akan menunjukkan sikap kooperatif dan mudah percaya (Chen, 2009), sehingga kecil kemungkinannya bagi individu ini untuk memunculkan perilaku RDB.

Hasil lain dari penelitian ini adalah tidak terdapatnya pengaruh trait extraversion terhadap perilaku RDB. Hasil ini bertolak belakang dengan penelitian yang dilakukan oleh Lucidi, Mallia, Lazuras \& Violani (2014), dimana salah satu sub trait extraversion yaitu excitement seeking berhubungan dengan perilaku melanggar aturan lalu lintas. Sebaliknya hasil penelitian lain menunjukkan tidak adanya hubungan trait extraversion dengan peningkatan jumlah kecelakaan dan RDB (Tao, Zhang \& Qu, 2017). Perbedaan hasil ini bisa disebabkan karakteristik sampel dan budaya yang berbeda. Seperti penelitian Lucidi, Mallia, Lazuras dan
Violani (2014) dilakukan Italia dengan rata-rata sampel berusia $>60$ tahun. Sedangkan hasil penelitian Tao, Zhang dan $\mathrm{Qu}$ (2017) sejalan dengan yang didapatkan oleh peneliti. Penelitian ini masih dilakukan di wilayah Asia dengan rata-rata sampel berusia 19-30 tahun. Temuan ini mungkin bisa dijadikan acuan bagi penelitian dimasa yang akan datang.

Hasil uji beda menunjukkan terdapat perbedaan perilaku RDB antara pengemudi laki-laki dan perempuan. Hasil ini juga sejalan dengan beberapa penelitian di luar negeri (Sarma, Carey, Kervick \& Bimpeh, 2013; Schwebel, Severson, Ball \& Rizzo, 2006). Pengemudi laki-laki lebih banyak ditemukan mengemudi dengan kecepatan diatas batas amam, ugal-ugalan, persepsi yang rendah akan terjadinya kecelakaan serta melanggar aturan lalu lintas dibandingkan pengemudi perempuan (Sarma, Carey, Kervick \& Bimpeh, 2013).

\section{SIMPULAN \& SARAN}

Dalam penelitian ini terlihat adanya pengaruh trait kepribadian terhadap perilaku RDB. Akan tetapi tidak semua trait yang mempengaruhi perilaku RDB. Hanya trait Agreeableness, Consciousness dan Neurotism yang secara signifikan mempengaruhi perilaku RDB. Selain itu, trait kepribadian mempengaruhi $15.9 \%$ perilaku RDB pada pengendara kendaraan bermotor di DKI Jakarta. Individu dengan perilaku mengemudi RDB akan merefleksikan trait Neurotism dan bertolak belakang dengan ciri-ciri individu dengan trait Agreeableness dan Conscientiousness. Selain itu, bisa dilihat perbedaan berdasarkan jenis kelamin dari pengemudi. Pengemudi laki-laki cenderung akan memunculkan perilaku RDB dibandingkan pengemudi perempuan.

\section{DAFTAR PUSTAKA}


Arthur Jr., W. \& Graziano, W.G., (1996). The five-factor model, conscientiousness, and driving accident involvement. Journal of Prevention. 64, 593-618.

Arthur Jr., W. \& Doverspike, D., (2001). Predicting motor vehicle crash involvement from a personality measure and a driving knowledge test. Journal of Prevention \& Intervention in the Community. 22, 35-42.

Azwar S. (2012). Reliabilitas dan Validitas. Yogyakarta. Pustaka Pelajar.

Bachoo, S., Bhagwanjee, A., \& Govender, K. (2013). The influence of anger, impulsivity, sensation seeking and driver attitudes on risky driving behaviour among post-graduate university students in Durban, South Africa. Accident Analysis and Prevention, 55, 67-76.

Bina, M., Graziano, F., \& Bonino, S. (2006). Risky driving and lifestyles in adolescence. Accident Analysis and Prevention, 38, 472-481.

Chen, C. F. (2009). Personality, safety attitudes and risky driving behaviorsEvidence from young Taiwanese motorcyclists. Accident Analysis and Prevention , 41, 963-968.

Constantinoua, E., Panayiotoua, G., Konstantinoua, N., Ladda, A. L., \& Kapardisb, A. (2011). Risky and aggressive driving in young adults: Personality matters. Accident Analysis and Prevention, 43, 1323-1331.

Creswell, J. W. (2012). Educational Research : Planning, Conducting, and Evaluating Quantitative and Qualitative Research. Boston, Pearson.

Dahlen, E. R., Martin, R. C., Ragan, K., \& Kuhlman, M. M. (2005). Driving anger, sensation seeking, impulsiveness, and boredom proneness in the prediction of unsafe driving. Accident Analysis \& Prevention, 37(2), 341-348.

Dahlen, D. R. \& White, R. P. (2006). The Big Five factors, sensation seeking, and driving anger in the prediction of unsafe driving. Personality \& Individual Difference, 41, 903-915.

Fernandez, D. H., Guererro, P. M., Chaparro, 1. S., Merino, L., \& Jenchura, E. C. (2016). Risky behavior in young adult pedestrians: Personality determinants, correlates with risk perception, and gender differences. Transportation Research Part F, 36, 14-24.

Jackson, S. L.(2006). Reseach Methods and Statistics : A Critical Approach. Edisi ke-2. Belmont, Thomson Wadsworth.

John, O. P.,\& Pervin, L. (1999). Handbook of Personality : Theory \& Research. New York, Guilford.

KORLANTAS POLRI. 2015. Data Jumlah Kecelakaan. (Online). http://korlantasirsms.info/graph/accidentData.

Lucidi, F., Mallia, 1, Lazuras, L. \& Violani C. (2014). Personality and attitudes as predictors of risky driving among older drivers. Accident Analysis and Prevention, 72, 318-324.

Mikler, S. R. \& Almakadma, A. (2016). Attitudes and behaviors towards risky driving among adolescents in Saudi Arabia. International Journal of Pediatrics and Adolescent Medicine. 3(2), 55-63.

Musselwhite, C. (2006). Attitudes towards vehicle driving behaviour: Categorising and contextualising risk. Accident Analysis and Prevention, 38, 324-334.

Sabates, L. A., Roca, J. S., \& Garcia, M. J., (2012). Emotional abilities as predictors of risky driving behavior among a cohort of middle aged drivers. Accident Analysis and Prevention, 45, 818-825.

Sarma, K.M., Carey, R. N., Kervick, A. A. \& Bimpeh, Y. (2013). Psychological factors associated with indices of risky, reckless and cautious driving in a national sample of drivers in the Republic of Ireland. Accident Analysis and Prevention, 50, 1226- 1235.

Schwebel, D. C., Severson, J., Ball, K.K. \& Rizzo, M. (2006). Individual difference factors in risky driving: The roles of anger/hostility, conscientiousness, and sensation-seeking. Accident Analysis and Prevention, 38, 801-810.

Sucha, M. \& Chernochova, D. (2016). Driver personality as a valid predictor of risky driving. Transportation Research Procedia, 14, 4286-4295.

Sârbescu, P., Costea, J. \& Rusu, S. (2012). Using the alternative Five Factor Personality Model to explain driving anger expression. Procedia - Social and Behavioral Sciences, 33, 273-277. 
Tao, D,. Zhang, R. \& Qu, X. (2017). The role of personality traits and driving experience in self-reportedrisky driving behaviors and accident risk among Chinese drivers. Accident Analysis and Prevention, 99, 228-235.

Wickens, C.M., Toplak, M.E., Wiesenthal, D.L., (2008). Cognitive failures as predictors of driving errors, lapses, and violations. Accid. Anal. Prev. 40 (3), 1223-1233.

Whiteside, S. P. \& Lynam, D. R. (2001). The Five Factor Model and impulsivity: using a structural model of personality to understand impulsivity. Personality and Individual Differences, 30, 669-689. Zhang, H., Qu, W., Ge, Y., Sun, X. \& Zhang, K. (2017). Effect of personality traits, age and sex on aggressive driving: Psychometric adaptation of the Driver Aggression Indicators Scale in China. Accident Analysis and Prevention. 103: 29-36.

World Health Organization, 2004. World Report on Road Traffic Injury Prevention.World Health Organization, Geneva. 